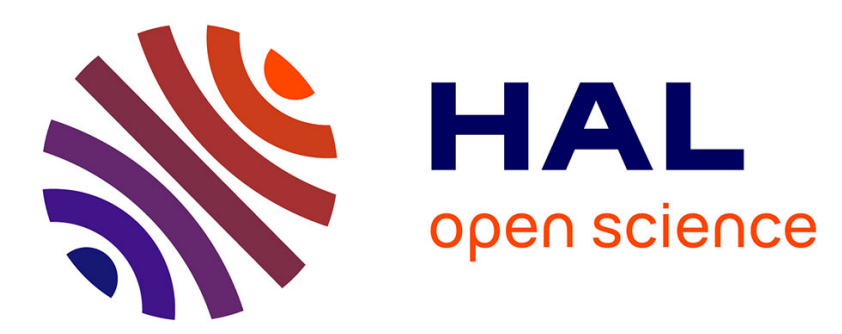

\title{
First observation of molecular and volume relaxation in glassy crystal cyanoadamantane
}

Michel Descamps, G. Odou, J.C. Caucheteux

\section{To cite this version:}

Michel Descamps, G. Odou, J.C. Caucheteux. First observation of molecular and volume relaxation in glassy crystal cyanoadamantane. Journal de Physique Lettres, 1985, 46 (6), pp.261-265. 10.1051/jphyslet:01985004606026100 . jpa-00232509

\section{HAL Id: jpa-00232509 https://hal.science/jpa-00232509}

Submitted on 1 Jan 1985

HAL is a multi-disciplinary open access archive for the deposit and dissemination of scientific research documents, whether they are published or not. The documents may come from teaching and research institutions in France or abroad, or from public or private research centers.
L'archive ouverte pluridisciplinaire HAL, est destinée au dépôt et à la diffusion de documents scientifiques de niveau recherche, publiés ou non, émanant des établissements d'enseignement et de recherche français ou étrangers, des laboratoires publics ou privés. 
Classification

Physics Abstracts

$61.40-61.50 \mathrm{~K}-76.60 \mathrm{E}$

\title{
First observation of molecular and volume relaxation in glassy crystal cyanoadamantane
}

\author{
M. Descamps, G. Odou and J. C. Caucheteux \\ Laboratoire de Dynamique des Cristaux Moléculaires (*), \\ Université de Lille I, 59655 Villeneuve d'Ascq Cedex, France
}

(Reçu le 6 juillet 1984, révisé le 3 décembre, accepté le 16 janvier 1985)

\begin{abstract}
Résumé. - Par diffusion des rayons X, nous avons étudié l'influence d'un recuit dans la phase vitreuse du cyanoadamantane obtenue par trempe de la phase plastique. Nous avons observé la contraction volumique spontanée, typique de l'état vitreux et nous montrons que des mouvements lents de réorientation moléculaire ont lieu alors qu'un ordre local antiparallèle se développe; nous observons des relaxations de grande amplitude de la diffusion aux points $\mathrm{X}$ de la zone de Brillouin avec des constantes de temps de plusieurs dizaines d'heures.
\end{abstract}

\begin{abstract}
The effect of annealing in the glassy crystal phase of cyanoadamantane has been investigated by $\mathrm{X}$-ray scattering. As is usually observed in glasses, we find a spontaneous volume contraction. At the same time we notice that slow molecular orientational relaxations take place which are connected to the growth of an antiparallel local order : we observe a large amplitude relaxation of the scattering at the $\mathrm{X}$ points of the Brillouin zone with characteristic times of several tens of hours.
\end{abstract}

If cyanoadamantane (CN-ADM) is rapidly cooled from the room-temperature plastic phase to a low enough temperature, it will not transform into the ordered monoclinic phase [1] but reaches an orientational glassy state $[2,3]$. The glassy transition has been observed at about $T_{\mathrm{g}}=170 \mathrm{~K}$. Through X-ray measurements of the plastic and " glassy crystal » phases, we have recently pointed out, in the latter phase, the presence of scattering spots at the X-boundary points of the Brillouin zones (B.Z.) [4]. This is a signature of a local antiparallel order of the dipolar $\mathrm{C} \equiv \mathrm{N}$ axes.

We have more recently observed that the corresponding correlation lengths, when measured at a certain temperature, strongly depend on the quenching rate : when the rate is decreased the spots become narrower and grow. Since a slow quenching includes some not-well defined annealing near $T_{g}$, we have studied the isothermal kinetics of the diffuse spot intensities, starting with rapidly quenched samples. That way we hope to get information about the time evolution of the glassy phase which is taken to be out of equilibrium. In this Letter we report the first results of this investigation. It has been performed with a four-circle diffractometer (Philips PW 1100) equipped with a focussed monochromatic $\mathrm{MoK} \alpha$ beam. Single crystals of the plastic phase could

$\left({ }^{*}\right)$ Unité associée au CNRS, $n^{\circ} 801$. 
be quenched easily in a gaseous nitrogen flow at the required temperature which was checked to $\pm 0.5^{\circ} \mathrm{C}$. The half-width at half maximum (HWHM) of the Bragg peaks was not modified by the quenching. It was verified that the sample remains long range fcc. The lattice constants were obtained from the set of (511) Bragg peaks : the lattice parameters were found to be equal to within a precision of about $\pm 0.003 \AA$ and the angles between the crystallographic axes were found to be equal to $90^{\circ}$ within an accuracy of $\pm 0.03^{\circ}$.

$\mathrm{X}$-ray scannings of the potentially intense zone boundary 121 spot [4] were repeated as a function of time and temperature in the $90 \mathrm{~K}-170 \mathrm{~K}$ range. At $92 \mathrm{~K}$ and $126 \mathrm{~K}$, no evolution of the scattering occurred within several tens of hours. On the other hand, during experiments performed between $150 \mathrm{~K}$ and $170 \mathrm{~K}$ we observed a slow growth and sharpening of the spot. The intensity at the top and the HWHM seem to approach a limit value at gradually decreasing rates of growth. The times required to seemingly come near to a saturation are typically 5 to 15 days. The evolution is sizeable in the studied temperature range : depending on the temperature we noticed a multiplication by 4 to 9 of the height of the spot.

The intensity maximum progressively shifts towards the exact position of the X-boundary point of the B.Z.

We here report (Fig. 1) an example of the evolution found during an anneal of about six days (137 hours) at $160 \mathrm{~K}$ i.e. ten degrees below the glassy transition.

Fitting the evolution of the intensity by exponential laws :

$$
I(\mathbf{Q}, t)=[I(\mathbf{Q}, 0)-I(\mathbf{Q}, \infty)] \exp \left(-\frac{t}{\tau(\mathbf{Q})}\right)+I(\mathbf{Q}, \infty)
$$

it has been found that no single relaxation time exists for the entire process. Two relaxation times, at least, are required : one, $\tau_{D}$ representing the range $0.5-7$ hours, and the other $\tau_{F}$, the range 50-137 hours. For the evolution of the intensity at the accurate $121 \mathrm{Q}$-position we have found :

$$
\tau_{\mathrm{D}} \approx 32 \text { hours; } \quad \tau_{\mathrm{F}} \approx 126 \text { hours }
$$

Two main experimental difficulties have limited the accuracy of this result.

- For practical reasons, the X-ray scattering measurements cannot begin right after the quenching and however high it is, the quenching rate itself is necessarily limited; so that the first scanning does not reveal a flat $I(Q)$ curve (Fig. 1a) and the characteristics at the very early time of the kinetics cannot be known.

- The annealing time could not be extended far enough so that the scattering reaches a well defined equilibrium value (if indeed such a value exists).

However the departure from linearity is clearly shown on the semi-logarithmic plot of $[I(\mathbf{Q}, \infty)-I(\mathrm{Q}, t)]$ (Fig. 1b). The experimental results clearly follow a slower time dependence at long times.

The HWHM of the diffuse spot is in inverse ratio to the coherence length $\xi$ of the local order. The narrowing of the spot thus accounts for the relaxation of the latter. In this respect the X-ray diagram is compatible with two images :

- The first would be homogeneous local ordering. In the orientationally disordered system under investigation the $\mathrm{X}$-ray scattered intensity in $\mathbf{Q}$ and $t$ is proportional to the susceptibility matrix $\chi(\mathbf{q}, t)$ expressed as follows in terms of equal time correlation functions of the $\boldsymbol{\mu}$ variables describing the molecular orientations :

$$
\chi(\mathbf{q}, t)=\sum_{r}\left\{\left\langle\boldsymbol{\mu}_{0}(t) \boldsymbol{\mu}_{r}(t)\right\rangle-\left\langle\boldsymbol{\mu}_{0}(t)\right\rangle\left\langle\boldsymbol{\mu}_{r}(t)\right\rangle\right\} \exp (i \mathbf{q r}) .
$$




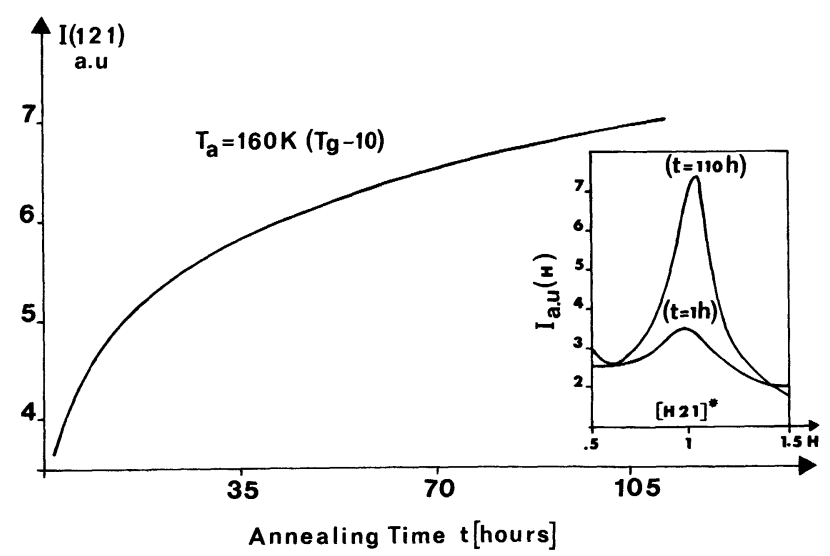

Fig. 1a. - Relaxation of the scattering at the $\mathrm{X}$ point : 121 , during an anneal at $T_{\mathrm{A}}=160 \mathrm{~K}\left(T_{\mathrm{g}}-10\right)$.

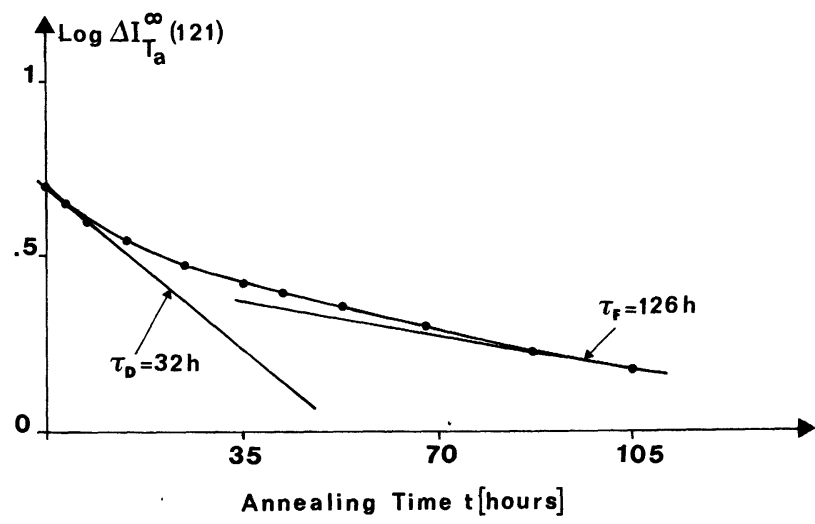

Fig. 1b. - Semi logarithmic plot of $[I(\mathbf{Q}, \infty)-I(\mathbf{Q}, t)]$ as a function of time $(\mathbf{Q} \equiv 121)$ during an anneal at $T_{\mathrm{A}}=160 \mathrm{~K}$.

A standard antiparallel O.Z. expression of the correlation functions thus leads to a Lorentzian centred on the $X$ point.

- The second one is that of clusters of ordered molecules imbedded in a matrix of orientationally disordered molecules. The growth thus occurs at isolated points of the crystal and this image requires two different environments in the structure. Such an assimilation of the ordered regions with microscopic crystals leads to the use of a Scherrer formula [5].

Such cautiousness in the possible description of the local order is necessary because of the current coexistence of two ways of describing the glassy state, either in terms of random network or of amorphous clusters [6].

Both interpretations give almost the same value for the coherence length. We find a 2-fold increase of $\xi$ between the first hour and the end of the anneal. At the same time the intensity at the top varies as $\xi^{2}$. More precisely :

$$
\begin{array}{ll}
\xi_{1 \mathrm{~h}}=13 \AA ; & I_{1 \mathrm{~h}}(\mathrm{X})=1.1 \text { a.u. } \\
\xi_{137 \mathrm{~h}}=25 \AA ; & I_{137 \mathrm{~h}}(\mathrm{X})=5.3 \text { a.u. }
\end{array}
$$


This kinetic effect provides evidence for individual molecular reorientations occurring below $T_{\mathrm{g}}$ over very long time scales (40 hours or more). In the present process, the dipolar axes reorient and rearrange themselves in a local antiparallel order. The three possible orientations of the corresponding local tetragonal cell are associated with three sets of diffuse spots [4]; at the end of the anneal, we could verify by scannings of several spots that the enlargement of the three different types of "domains " is the same. The growth is thus homogeneous regarding the orientations and apparently it does not affect the average cubic symmetry.

An important issue is that of the existence or non existence of a connection between the local structure just observed and the long range orientational order of the monoclinic phase which is stable at the same temperature.

When analysing the structure of the latter [1] it appears that the molecular centres of mass arrange themselves in a pseudo fcc lattice. But within this description, the dipolar axes are located along a pseudo three-fold direction and not along the four-fold axes as is the case in the plastic and glassy crystal phases [7,8]. The long range antiparallel planes of the monoclinic structure are thus of a pseudo $\left(\begin{array}{lll}1 & 1 & 0\end{array}\right)$ type and not of $\left(\begin{array}{lll}1 & 0 & 0\end{array}\right)$ type as found locally under $T_{\mathrm{g}}$. The growth of an orientational order evolving to a monoclinic order would thus produce spots located at the $\mathrm{L}$ points of the B.Z. and not at the $\mathrm{X}$ points. Besides, the transition to the monoclinic phase can be detected through a diffraction experiment. In fact, it actually occurs above $T_{\mathrm{g}}$ when the sample is upquenched from the annealing temperature. It is revealed by a fast and significant increase of the mosaic spread and ends with the destruction of the single crystal.

While we did not precisely focus on a study of the volume relaxation mechanism, we have noted a spontaneous isothermal contraction during the annealing. In the present experiment, the measurements of the cubic lattice parameters have given the following values :

$$
\begin{aligned}
& a_{1 \mathrm{~h}}=9.683 \pm 0.003 \AA \\
& a_{137 \mathrm{~h}}=9.663 \pm 0.003 \AA
\end{aligned}
$$

i.e. a linear contraction of more than $0.2 \%$.

For the time being, we cannot assert that the observed short range order is typical of the glassy crystal phase of CN-ADM because to do so would require measurements of the diffuse scattering above $T_{\mathrm{g}}$, in the so-called metastable phase. Unfortunately such measurements are impossible with the required precision because the cubic crystal is not stable long enough during an upquenching. A more complete analysis of the revealed molecular relaxation phenomenon occurring simultaneously with a volume contraction classically observed in glasses [9], would enable a theoretical microscopic description of the glassy state to be attempted.

\section{Acknowledgments.}

We are very grateful to $\mathrm{M}$. Muller for growing beautiful single crystals and Dr. W. Briels for reading the manuscript.

We also thank Dr. J. L. Sauvajol for kind discussions.

The DRET is acknowledged for partial support of this work. 


\section{References}

[1] Foulon, M., Amoureux, J. P., Sauvajol, J. L., Cavrot, J. P., Muller, M., J. Phys. C 17 (1984) 4213.

[2] Foulon, M., AmoureuX, J. P., Sauvajol, J. L., Lefebvre, J., Descamps, M., J. Phys. C 16 (1983) L265.

[3] Adachi, K., Suga, H., Seki, S., Bull. Chem. Soc. Jpn 41 (1968) 1073.

[4] Descamps, M., Caucheteux, C., Odou, G., Sauvajol, J. L., J. Physique Lett. 45 (1984) L-719.

[5] GuINIER, A., Théorie et technique de la radiocristallographie (Dunod, Paris) 1956.

[6] JohaRi, G. P., Ann. N.Y. Acad. Sci. 279 (1976) 117.

[7] Amoureux, J. P., Sauvajol, J. L., Bee, M., Acta Crystal. A 37 (1981) 97.

[8] Foulon, M., Lefebvre, J., Amoureux, J. P., Muller, M., Magnier, D., submitted for publication.

[9] Kovacs, A. J., Hutchinson, J. M., AkLouis, J. J., The structure of non crystalline materials P. H. Gaskell, ed. (Taylor et Francis) 1977. 